\title{
Information about secondary prevention in coronary patients: a comparison between Italian and Brazilian Application of MICRO-Q Questionnaire
}

\section{Informazioni sulla prevenzione secondaria nei coronariopatici: confronto tra una applicazione italiana e una brasiliana del Questionario MICRO-Q}

\author{
Gabriela Lima de Melo Ghisi1, Cláudia Medeiros Leite1, \\ Marinella Sommaruga2 ${ }^{2}$, Magnus Benetti ${ }^{1}$
}

\begin{abstract}
Information about secondary prevention in coronary patients: a comparison between Italian and Brazilian Application of MICRO-Q Questionnaire. G. Lima de Melo Ghisi, C. Medeiros Leite, M. Sommaruga, M. Benetti.

Background: The MICRO-Q (MaugerI CaRdiac preventiOn Questionnaire) is a self-administered questionnaire addressed to the evaluation of information regarding secondary prevention in patients with coronary heart disease (CHD). The aim of this study was to compare the results from Italian and Brazilian application of MICRO-Q.

Methods: the instrument was administered to 500 coronary patients (250 Italian and 250 Brazilian), 117 female and 383 male, aged on average 61.16 years $(\mathrm{SD}=9.74$; range: 33-86), participants of cardiac rehabilitation programs. The Italian MICRO-Q has 26 items, 18 true statements and 8 false, with responses true, false and 'don't know', with three separate scores: correct, uncorrect and uncertain. The
\end{abstract}

Brazilian MICRO-Q has 25 items, 18 true statements and 7 false, with the same responses and scores. To verify and compare results we used Independent-Sample T Test, ANOVA and Bonferroni Post-hoc.

Results: The analysis of mean total scores of Italian and Brazilian applications showed statistically significant differences for correct answers $(p<0.001)$ and for 'don't know' answers $(\mathbf{p}<0.001) .18$ statements had significant $(p<0.005)$ differences between applications in the two countries.

Conclusion: Despite differences between Italy and Brazil, the analysis of MICRO-Q applications showed a similar mean score percent of correct answers, indicating enough knowledge about secondary prevention of CHD.

Keywords: knowledge, coronary heart disease, cardiac rehabilitation, questionnaire, socio-economic differences.

Monaldi Arch Chest Dis 2010; 74: 16-21.

1 State University of Santa Catarina (UDESC), Florianópolis, Santa Catarina, Brazil. Adress: Rua Pascoal Simoni, 358, Coqueiros, Florianópolis, SC, Brazil. Phone: +55 (48)3321-8600. Fax: +55(48)3321-8607.

2 Psychology Unit, Maugeri S. Foundation, Care and Research Institute, Tradate, Varese, Italy.

Corresponding author: Gabriela Lima de Melo Ghisi; Rua do Rocio, 52, apto 12, Vila Olímpia, São Paulo - SP, Brazil. 04552-000; E-mail address: gabriela.ghisi@gmail.com

\section{Introduction}

Cardiovascular diseases (CVD) are responsible for 16.7 millions of deaths around the world each year and, according World Health Statistics (2008), and they are no longer a problem only for rich countries, although they are still the leading cause of death in developed countries [1]. By the year of 2002, coronary heart disease (CHD) caused almost 40.000 deaths in Italy, being the main cause of death in men not only in this country but in all European Union. In the same year, in Brazil, it was seen that almost 140.000 people died from this disease, putting Brazil as the $9^{\text {th }}$ country in CHD deaths [2].

Although the numbers of deaths from CVD are significant, 20 million of people survive from heart attacks and strokes each year, requiring constant clinical care and causing high costs to governments [1-3].

Programs directed toward the control of coronary heart disease - named cardiac rehabilitation programs -, defined as "a combination of the correct and practical use of guidelines, appropriate consultation, supplies of drugs and ancillary services, and education" are the best way to improve functional capacity and quality of life, considered to risk reduce factors and create a sense of well-being and optimism about the future $[4,5]$.

As patient education is considered a "combination of learning experiences influencing behaviour changes, producing changes in knowledge, attitudes and skills needed to maintain and improve health", the environment is an important factor related to this achievement of knowledge [6]. 
In order to evaluate information in patients with coronary heart disease, MICRO-Q (MaugerI CaRdiac prevention Questionnaire) was developed and validated in Italian [7], followed by the Portuguese validation [8].

The MICRO-Q covers four domains of knowledge (risk factors and lifestyle, diet, pre-admission avoidable delay, and cardiac disease) [7] directly involved in cardiac rehabilitation programs, for short and long terms. The short-term goals include: physical reconditioning to daily activities, education of patients and their families about the disease process, and admissions and psychological support during the early recovery phase of the disease. The longterm goals include: identifying and treating risk factors influencing the evolution of the disease, teaching and reinforcing health behaviours that improve the prognosis and improve physical fitness, and facilitating the patient's return to work activities and leisure [9].

Previous data [10-14] have shown a significant relationship between knowledge and these domains. For instance, knowledge can lead patients to make changes in lifestyle such as diet, physical activity; moreover, the perception of the disease and beliefs about causes, symptoms and treatment of coronary artery disease are often influenced by knowledge [10-13]. In addition, according to Kayaniyil and colleagues [14]: "the non-understanding of the disease and related factors can cause emotional changes, inappropriate behaviour, non-adherence to treatment and progression of the disease".

The purpose of this study was to compare the results from Italian and Brazilian validation of MICRO-Q and to evaluate knowledge in coronary patients in cardiac rehabilitation programs in these two environments.

\section{Methods}

\section{The Questionnaire}

The MICRO-Q (MaugerI CaRdiac preventiOn Questionnaire) is a self-administered questionnaire addressed to the evaluation of information regarding secondary prevention in patients with coronary heart disease [7].

The Questionnaire covers four domains of knowledge [7]:

- Risk factors and lifestyle domain: brings 9 items related to myocardial infarction, the meaning of risk factor, destiny and belief, smoking, psychological stress, levels of cholesterol, hypertension, blood sugar concentration and physical activity.

- Diet domain: 8 items related to the nutritional plan for persons with coronary disease, for instance, how you should cook your food and the consumption of salt, fish, extra virgin olive oil and fibres.

- Pre-admission avoidable delay domain: 4 items that brings alternatives of what coronary patients should do if they experience an episode of chest pain or discomfort (for example, drive your car to the emergency room or take a sublingual nitroglycerin).
- Cardiac disease domain: 7 items that cover information about diagnosis, surgical procedures and other issues (as sexual activity, cardiac pacing and treadmill test).

The original version was developed in Italian and consisted of 26 items, 18 true statements and 8 false ones, with responses true, false and 'don't know'. There are three separate scores, each one ranging from 0 to 26: correct (number of items answered correctly), uncorrect (number of items wrongly answered), uncertain (number of items answered 'don't know') [7].

The Brazilian version was developed in South of Brazil and consisted of 25 items, 18 true statements and 7 false ones, with the same responses as original version (true, false and 'don't know'). In the process of translation and cross-culturally adaptation it was verified that the item 15 was not a Brazilian food habit ("It is good to eat a little bit of cheese at the end of each meal"). So, this item was excluded in the Portuguese version, with the agreement of the original author. Because of that, in the Brazilian MICRO-Q, the items were distributed in the four domains as described: risk factors and lifestyle (9 items), diet (7 items), pre-admission avoidable delay (4 items) and cardiac disease (5 items) [8].

The validation of the original and the Brazilian version of MICRO-Q showed similarities. Spearman Rho correlation coefficient (test-retest) for correct responses was 0.72 at the original validation and 0.65 at the Brazilian validation, and the Cronbach's Alpha value of the reliability analysis was 0.68 at the original validation and 0.64 at the Brazilian one $[7,8]$.

\section{Participants}

For validation, the Italian version of MICRO-Q was administered to 250 coronary patients (206 males, 44 females), aged on average 61.38 years old $(\mathrm{SD}=10.15$; range $=33-80)$, admitted to in-hospital cardiac rehabilitation programs in different geographical areas of Italy, after an episode of acute myocardial infarction (AMI) [7].

For the Portuguese Validation, MICRO-Q was administered to 212 coronary patients (144 males, 68 females) aged on average 60.72 years $(\mathrm{SD}=9.4$; range: $35-86$ ), participants of cardiac rehabilitation programs in South Brazil, with diagnosis of coronary artery disease more than 1 month. For this comparison, the sample was expanded to 250 patients [8].

Characteristics of population for both studies are shown on Table 1.

\section{Procedures}

Data collection was performed by adding the two data from validation of MICRO-Q' studies.

All statistical analysis was performed by the SPSS, Statistical Package for the Social Sciences, and the significance level adopted was 0.005 .

To verify and compare results from both applications of MICRO-Q (Italian and Brazilian ones) we used Independent-Sample T Test. Statistical significances for the subgroups analysis (including characteristics of populations and mean total scores) were calculated using the ANOVA and Bonferroni Post-hoc. 
Table 1. - Characteristics of Coronary Population in both studies

\begin{tabular}{|c|c|c|c|c|c|c|c|c|}
\hline \multirow[t]{2}{*}{ Variable } & \multirow[t]{2}{*}{ Category } & \multicolumn{2}{|c|}{$\begin{array}{l}\text { Italian Version } \\
\quad(\mathbf{n}=\mathbf{2 5 0})\end{array}$} & \multicolumn{2}{|c|}{$\begin{array}{c}\text { Brazilian Version } \\
\qquad(\mathrm{n}=\mathbf{2 5 0})\end{array}$} & \multirow[b]{2}{*}{$\mathbf{P}$} & \multicolumn{2}{|c|}{$\begin{array}{c}\text { Total } \\
(\mathbf{n}=500)\end{array}$} \\
\hline & & $\mathbf{n}$ & $\%$ & $\mathbf{n}$ & $\%$ & & $\mathbf{n}$ & $\%$ \\
\hline \multirow[t]{2}{*}{ Gender } & Male & 206 & $17.6 \%$ & 177 & $29.2 \%$ & 0.002 & 383 & $76.6 \%$ \\
\hline & Female & 44 & $82.4 \%$ & 73 & $70.8 \%$ & & 117 & $23.4 \%$ \\
\hline \multirow[t]{3}{*}{ Age } & $<65$ years old & 136 & $55.5 \%$ & 156 & $65.8 \%$ & 0.013 & 292 & $58.4 \%$ \\
\hline & $>65$ years old & 109 & $44.5 \%$ & 81 & $34.2 \%$ & & 190 & $38 \%$ \\
\hline & Don't answered & 5 & $2 \%$ & 13 & $5.2 \%$ & & 18 & $3.6 \%$ \\
\hline \multirow[t]{10}{*}{ Occupation } & Retired & 134 & $53.6 \%$ & 105 & $42 \%$ & 0.023 & 239 & $47.8 \%$ \\
\hline & Factory-worker & 23 & $9.2 \%$ & 30 & $12 \%$ & & 53 & $10.6 \%$ \\
\hline & Office-worker & 22 & $8.8 \%$ & 23 & $9.2 \%$ & & 45 & $9 \%$ \\
\hline & Tradesman/dealer & 17 & $6.8 \%$ & 19 & $7.6 \%$ & & 36 & $7.2 \%$ \\
\hline & Householder & 15 & $6 \%$ & 29 & $11.6 \%$ & & 44 & $8.8 \%$ \\
\hline & Other & 12 & $4.8 \%$ & 4 & $1.6 \%$ & & 16 & $3.2 \%$ \\
\hline & Manager & 10 & $4.0 \%$ & 23 & $9.2 \%$ & & 33 & $6.6 \%$ \\
\hline & Professional & 9 & $3.6 \%$ & 8 & $3.2 \%$ & & 17 & $3.4 \%$ \\
\hline & Businessman & 7 & $2.8 \%$ & 9 & $3.6 \%$ & & 16 & $3.2 \%$ \\
\hline & Unemployed & 1 & $0.4 \%$ & 0 & $0 \%$ & & 1 & $0.2 \%$ \\
\hline \multirow[t]{3}{*}{ Education Level } & $\leq 8$ years & 183 & $73.2 \%$ & 123 & $49.8 \%$ & 0.000 & 306 & $61.2 \%$ \\
\hline & $>8$ years & 67 & $26.8 \%$ & 124 & $50.2 \%$ & & 191 & $38.2 \%$ \\
\hline & Don't answered & 0 & $0 \%$ & 3 & $1.2 \%$ & & 3 & $0.6 \%$ \\
\hline
\end{tabular}

\section{Results}

Results of Italian application showed a mean score of correct answers of $18.9(\mathrm{SD}=3.25)$; a mean score of uncorrect answers of $2.97(\mathrm{SD}=1.66)$; and, a mean score of uncertain answers of 3.97 $(\mathrm{SD}=3.56)$. For Brazilian application these mean scores are, respectively, $19.9(\mathrm{SD}=2.36) ; 3.04$ $(\mathrm{SD}=1.43)$; and, $2.06(\mathrm{SD}=2.26)$.

The analysis of mean total scores of Italian and Brazilian applications showed statistically significant differences for correct answers $(\mathrm{p}<0.001)$ and for 'don't know' answers $(\mathrm{p}<0.001)$.

The frequency analysis of each item in the three scales in Italian and Brazilian application is showed on Table 2.

The statistical tests performed indicated that 18 of the 25 statements (not included item 15) had significant $(p<0.005)$ differences between the two countries applications of MICRO-Q. The items which a lower rate of correct scales was observed were questions 2 , 7, 12, 22 in Italy and 2, 22 for Brazilian Application.

Comparing Brazilian and Italian application, we found that in both studies (Brazil 84\% and Italy $79.3 \%$ ) patients believe that 'myocardial infarction and/or angina are caused by risk factors'. The idea that risk factors being the cause of symptoms and acute events can delay the comprehension of the real cause of this events, which is important information that CHD patients must know [15, 16].

In the fifth question, $12 \%$ of Brazilian patients and $29.7 \%$ Italians thought that "coronary artery bypass graft is a complete and definitive treatment for coronary artery disease'. Despite that, more than $40 \%$ of Italian and $36 \%$ of Brazilian have surpris- ingly an uncertainly idea about this statement. This kind of belief could be an obstacle in the achievement of lifestyle modifications [17].

More than $67 \%$ of Italian patients thought that 'people who feel under stress cannot do anything to change this' and $68 \%$ answered as true the statement that 'people who have cardiac disease can say that it is only because of destiny', which would not help coronary patients to reach the correct treatment and to change their lifestyle [17]. However, Brazilian application didn't show this kind of belief: only $5.6 \%$ believed that stress cannot be modified and $3.6 \%$ thought that destiny is the cause of their disease. Patients can protect themselves by learning to recognize the signs and symptoms of stress and take steps to reduce its harmful effects $[17,18]$.

Almost $30 \%$ of Italian subjects and $20 \%$ of Brazilian had uncertainty information about the need of sublingual nitrate (TNG) in case of chest pain. When this pain persists, $70 \%$ of Italian patients wrongly believed that they should contact their general practitioner by phone. This incorrect idea is also believed in Brazilian patients: 74\% thought that too. Despite these results, in the Italian study $78.8 \%$ of patients believed correctly that they should not drive their car to the closest first-aid facility and Brazilian patients also had this correct knowledge (74\%).

When asked if is true the statement that "people who have high levels of blood cholesterol, diabetes and/or overweight must learn to choose an adequate diet', $97.6 \%$ of Italian patients and $98.4 \%$ of Brazilian patients answered correctly this question. The result showed that a majority of sample have knowledge regarding this important statement, which can be decisive on their treatment [18]. 
Table 2. - Frequency analysis of each item in the three scales in Italian and Brazilian application

\begin{tabular}{|c|c|c|c|c|c|c|c|}
\hline & \multicolumn{3}{|c|}{ Italian Application } & \multicolumn{3}{|c|}{ Brazilian Application } & \multirow[b]{2}{*}{$\mathbf{p}$} \\
\hline & Correct & Uncorrect & Uncertain & Correct & Uncorrect & Uncertain & \\
\hline Q1 & $232(93.5 \%)$ & $5(2 \%)$ & $11(4.4 \%)$ & $241(96.4 \%)$ & $5(2 \%)$ & $4(1.6 \%)$ & 0.161 \\
\hline Q2 & $6(2.4 \%)$ & $195(79.3 \%)$ & $45(18.3 \%)$ & $15(6 \%)$ & $210(84 \%)$ & $25(10 \%)$ & 0.002 \\
\hline Q3 & $148(61.4 \%)$ & $73(30.3 \%)$ & $20(8.3 \%)$ & $228(91.2 \%)$ & $5(2 \%)$ & $17(6.8 \%)$ & 0.000 \\
\hline Q4 & $142(57.7 \%)$ & $45(18.3 \%)$ & $59(24 \%)$ & $174(69.6 \%)$ & $53(21.2 \%)$ & $23(9.2 \%)$ & 0.000 \\
\hline Q5 & $71(28.9 \%)$ & $73(29.7 \%)$ & $102(41.5 \%)$ & $129(51.6 \%)$ & $31(12.4 \%)$ & $90(36 \%)$ & 0.000 \\
\hline Q6 & $207(82.8 \%)$ & $3(1.2 \%)$ & $40(16 \%)$ & $222(88.8 \%)$ & $4(1.6 \%)$ & $24(9.6 \%)$ & 0.034 \\
\hline Q7 & $32(12.8 \%)$ & $171(68.4 \%)$ & $47(18.8 \%)$ & $233(93.2 \%)$ & $9(3.6 \%)$ & $8(3.2 \%)$ & 0.000 \\
\hline Q8 & $203(81.2 \%)$ & $16(6.4 \%)$ & $31(12.4 \%)$ & $228(91.2 \%)$ & $11(4.4 \%)$ & $11(4.4 \%)$ & 0.001 \\
\hline Q9 & $232(92.8 \%)$ & $7(2.8 \%)$ & $11(4.4 \%)$ & $221(88.4 \%)$ & $15(6 \%)$ & $14(5.6 \%)$ & 0.467 \\
\hline Q10 & $241(97.6 \%)$ & $2(0.8 \%)$ & $4(1.6 \%)$ & $246(98.4 \%)$ & $2(0.8 \%)$ & $2(0.8 \%)$ & 0.525 \\
\hline Q11 & $106(79.4 \%)$ & $10(4 \%)$ & $41(16.6 \%)$ & $217(86.8 \%)$ & $16(6.4 \%)$ & $17(6.8)$ & 0.001 \\
\hline Q12 & $38(15.3 \%)$ & $168(67.5 \%)$ & $43(17.3 \%)$ & $225(90 \%)$ & $14(5.6 \%)$ & $11(4.4 \%)$ & 0.000 \\
\hline Q13 & $215(86.3 \%)$ & $4(1.6 \%)$ & $30(12 \%)$ & $240(96 \%)$ & $7(2.8 \%)$ & $3(1.2 \%)$ & 0.000 \\
\hline Q14 & $209(83.6 \%)$ & $8(3.2 \%)$ & $33(13.2 \%)$ & $248(99.2 \%)$ & $2(0.8 \%)$ & 0 & 0.000 \\
\hline Q15 & $113(45.2 \%)$ & $45(18 \%)$ & $90(36 \%)$ & - & - & - & - \\
\hline Q16 & $220(88.4 \%)$ & $2(0.8 \%)$ & $27(10.8 \%)$ & $195(78 \%)$ & $47(18.8 \%)$ & $8(3.2 \%)$ & 0.000 \\
\hline Q17 & $229(91.6 \%)$ & $3(1.2 \%)$ & $18(7.2 \%)$ & $228(91.2 \%)$ & $5(2 \%)$ & $17(6.8 \%)$ & 0.642 \\
\hline Q18 & $176(71 \%)$ & $9(3.6 \%)$ & $63(25.4 \%)$ & $243(97.2 \%)$ & $2(0.8 \%)$ & $5(2 \%)$ & 0.000 \\
\hline Q19 & $199(79.6 \%)$ & $14(5.6 \%)$ & $37(14.8 \%)$ & $227(90.8 \%)$ & $13(5.2 \%)$ & $10(4 \%)$ & 0.002 \\
\hline Q20 & $240(96 \%)$ & $2(0.8 \%)$ & $8(3.2 \%)$ & $203(81.2 \%)$ & $33(13.2 \%)$ & $14(5.6 \%)$ & 0.001 \\
\hline Q21 & $174(69.6 \%)$ & $2(0.8 \%)$ & $74(29.6 \%)$ & $196(78.4 \%)$ & $6(2.4 \%)$ & $48(19.2 \%)$ & 0.003 \\
\hline Q22 & $32(12.9 \%)$ & $175(70.6 \%)$ & $41(16.5 \%)$ & $29(11.6 \%)$ & $185(74 \%)$ & $36(14.4 \%)$ & 0.861 \\
\hline Q23 & $215(86.7 \%)$ & $4(1.6 \%)$ & $29(11.7 \%)$ & $216(86.4 \%)$ & $5(2 \%)$ & $29(11.6 \%)$ & 0.880 \\
\hline Q24 & $197(78.8 \%)$ & $29(11.6 \%)$ & $24(9.6 \%)$ & $185(74 \%)$ & $47(18.8 \%)$ & $18(7.2 \%)$ & 0.000 \\
\hline Q25 & $187(75.1 \%)$ & $13(5.2 \%)$ & $49(19.7 \%)$ & $225(54.6 \%)$ & $9(3.6 \%)$ & $16(6.4 \%)$ & 0.001 \\
\hline Q26 & $231(92.8 \%)$ & $2(0.8 \%)$ & $16(6.4 \%)$ & $184(44.3 \%)$ & $6(2.4 \%)$ & $60(24 \%)$ & 0.000 \\
\hline
\end{tabular}

With respect of the four domains of knowledge, Brazilian patients had a mean score of correct answers for risk factors and lifestyle of 7.34, which represents $81.5 \%$ of knowledge in this domain. In Italy, coronary patients showed a mean score for these answers of 6.44 , which represents $71.5 \%$ of knowledge. This difference is statistically significant $(\mathrm{p}<0.001)$. In diet domain, Brazilian patients had a mean score of correct answers of $6.42(91.71 \%$ of knowledge), and Italian patients had 6.63 $(82.87 \%)$. About pre-admission and avoidable delay questions, Brazilian and Italian patients acquired a mean score of correct answers of $2.52(63 \%)$ and $2.47(61.75 \%)$, respectively. And, for cardiac disease domain, Brazilian patient had a mean score of correct answers of 3.73, which represents $74.6 \%$ of knowledge in this domain. In Italian application, we showed a mean score of 3.36 , which represents $67.2 \%$ of knowledge. This difference is also statistically significant $(\mathrm{p}<0.001)$. All results from the four domains of MICRO-Q are showed on Table 3.

Another analysis was performed according to patient's characteristics, such as age, gender, occupation and educational level. For the scores (correct and uncertain), statistical differences were observed between applications (Brazil and Italy) in all these characteristics. Despite the fact that in both studies socioeconomic level was the most important factor related to uncorrect answers, this comparison showed that others (as occupation) can influence knowledge of coronary patients.

\section{Discussion}

Despite differences in scale and dimension territorial, culture and politics history, population density, access of health services between Italy and Brazil, the analysis of MICRO-Q applications showed a mean score of correct answers that represents knowledge of $79.6 \%$ in Brazilian patients and $72.69 \%$ in Italian patients. Although this difference is statistically significant, both results showed enough knowledge about secondary prevention comparing to other studies that estimated that 30 to $78 \%$ of coronary patients do not fully understand educational information provided to them [18].

The failure of current cardiac teaching programs to promote behavioural changes may be due to the lack of an individualised approach, and to inappropriate timing of the information. Programs, often not tailored to patients' individual needs, should be systematic and easily adaptable to suit specific individual requirements.

The differences between Brazilian and Italian application in 18 of 25 items demonstrate that habits, environment and economy are factors directly related 
Table 3. - Results from the four domains of knowledge of MICRO-Q

\begin{tabular}{|c|c|c|c|c|c|c|c|}
\hline \multirow[b]{2}{*}{ Areas } & \multicolumn{3}{|c|}{ Italian Application } & \multicolumn{3}{|c|}{ Brazilian Application } & \multirow[b]{2}{*}{$\mathbf{p}$} \\
\hline & Correct & Uncorrect & Uncertain & Correct & Uncorrect & Uncertain & \\
\hline $\begin{array}{l}\text { Risk factors and lifestyle } \\
0-9\end{array}$ & $6.44(1.45)^{*}$ & $1.26(0.84)$ & $1.21(1.47)^{* *}$ & $7.34(1.03)^{*}$ & $1.22(0.68)$ & $0.45(0.76) * *$ & $\begin{array}{l}* p<0.001 \\
* p<0.001\end{array}$ \\
\hline $\begin{array}{l}\text { Diet } \\
\text { Italian 0-8 } \\
\text { Brazilian 0-7 }\end{array}$ & $6.63(1.31)^{*}$ & $0.34(0.61)$ & $1(1.24)^{* *}$ & $6.42(0.88)^{*}$ & $0.36(0.63)$ & $0.22(0.62)^{* *}$ & $\begin{array}{l}* \mathrm{p}=0.03 \\
* * \mathrm{p}<0.001\end{array}$ \\
\hline $\begin{array}{l}\text { Avoidable Delay } \\
0-4\end{array}$ & $2.48(0.92)$ & $0.82(0.58)^{*}$ & $0.69(1.04)$ & $2.52(0.96)$ & $0.96(0.67)^{*}$ & $0.56(1.21)$ & $* \mathrm{p}=0.01$ \\
\hline $\begin{array}{l}\text { Cardiac Disease } \\
0-5\end{array}$ & $3.36(1.04)$ & $0.54(0.66)$ & $1.07(1.10)$ & $3.73(1.02)$ & $0.42(0.6)$ & $1.85(0.98)$ & - \\
\hline
\end{tabular}

Table 4. - Scores for the three scales from both Studies according to gender, age, educational level and occupation

\begin{tabular}{|c|c|c|c|c|c|c|c|}
\hline & & \multicolumn{3}{|c|}{ Italian Application } & \multicolumn{3}{|c|}{ Brazilian Application } \\
\hline & & Correct & Uncorrect & Uncertain & Correct & Uncorrect & Uncertain \\
\hline \multirow[t]{2}{*}{ Gender } & Female & $18.43(3.5)$ & $3.02(1.64)$ & $4.16(3.61)$ & $19.78(2.12)$ & $3.15(1.59)$ & $2.07(1.95)$ \\
\hline & Male & $19.00(3.2)$ & $2.96(1.67)$ & $3.93(3.56)$ & $19.95(2.46)$ & $3.00(1.36)$ & $2.05(2.38)$ \\
\hline \multirow[t]{2}{*}{ Age } & $<65$ years & $19.26(3.17)$ & $2.75(1.47)$ & $3.89(3.59)$ & $19.83(2.4)$ & $3.15(1.54)$ & $2.03(2.19)$ \\
\hline & $\geq 65$ years & $18.57(3.26)$ & $3.19(1.83)$ & $4.00(3.47)$ & $20.10(2.31)$ & $2.74(1.16)$ & $2.15(2.45)$ \\
\hline \multirow[t]{2}{*}{ Educational Level } & $\leq 8$ years & $18.44(3.36)$ & 3.11 (1.69) & $4.27(3.76)$ & $18.55(2.96)$ & $2.93(1.52)$ & $3.52(2.89)$ \\
\hline & $>8$ years & $20.18(2.56)$ & $2.57(1.5)$ & $3.16(2.81)$ & $20.20(2.06)$ & $2.98(1.33)$ & $1.84(2.19)$ \\
\hline \multirow[t]{5}{*}{ Occupation } & Retired & $18.57(3.29)$ & $3.24(1.70)$ & $4.01(3.59)$ & $20(2.22)$ & $2.96(1.2)$ & $2.03(2.32)$ \\
\hline & Householder & $18.27(3.97)$ & $3.33(1.84)$ & $4.13(3.98)$ & $19.52(2.37)$ & $3.14(1.74)$ & $2.34(2.21)$ \\
\hline & Business* & $19.95(2.85)$ & $2.68(1.59)$ & $3.3(2.24)$ & $20.50(2.73)$ & $3.25(1.49)$ & $1.25(1.75)$ \\
\hline & Professional & $19.33(2.83)$ & $3.11(1.54)$ & $3.44(2.45)$ & $19.84(3.01)$ & $3(1.59)$ & $2.16(2.50)$ \\
\hline & Other** & $18.69(3.27)$ & $2.22(1.29)$ & $4.92(3.89)$ & $19.87(2.26)$ & $3.12(1.54)$ & $2.03(2.16)$ \\
\hline
\end{tabular}

* Business $=$ businessman, manager, dealer, office-worker. $* *$ Other $=$ unemployed, factor-worker, other.

Statistical differences $(\mathrm{p} \leq 0.05)$ were pointed out by narrow numbers between studies

to knowledge and that when an instrument is used in different realities it must be adapted for that. Although there is a difference, we identified in both countries a linear relationship between the amount of information given and the knowledge acquired, which means that strategies should be taken to improve patients' adherence and education [19].

The questions 2, 7 and 12 had lower rates in the Italian Application, which could be related to poor knowledge about risk factors and lifestyle. In Brazil we observed the same behaviour. Most of patients think that treatment and modifications in lifestyle and risk factors are not related, which can be a wrong idea and an obstacle to achieve a better health [20].

Socioeconomic level is an important factors related to the achievement of knowledge whose and that influence was observed in both studies (Italian and Brazilian validation) and in this comparison. For many studies socioeconomic status is consistently among the most fundamental determinants of health status. Much of this socioeconomic status re- lationship can be attributed to CVD and the combined effects of disparities in health-related behaviours, environmental conditions, social structures, and the contact and delivery of health care. Because these factors change in developed and developing countries and because they are modifiable, it is important to compare countries to find ways to reach people with different ways of life [21-24].

The characteristics of rehabilitation programs and culture of the countries are also aspects that should be taken into account to analyze these differences. Still, other factors may be pointed out; for instance: the health system of each country, facility to get to the places of rehabilitation programs, physical structure of the programs and the medical pre-rehabilitation participation.

Brazil and Italy are experiencing a transitional phase in which degenerative and infectious disease are declining and CVD are predominating in several regions. At the same time, life expectancy continues to increase, and smoking, high-fat diets and secondary lifestyles are becoming common $[1,3]$. 
The data also showed that, despite the good knowledge by coronary patients of cardiac rehabilitation programs, a small portion of the coronary patients are in these programs. Additionally, reflecting on the meaning of 'health' in our reality, this study appears as an opportunity to think about improving the quality of life of patients through health promotion. In this case, promoting health means taking action on social security rights of citizens and the economic structures that perpetuate social inequalities. Health should be dynamic, mediated by a set of social, economic, cultural, political, environmental and educational factors. Education is associated with health, thus promoting health also means to intervene on education.

\section{Riassunto}

Introduzione: Il MICRO-Q (MaugerI CaRdiac prevention Questionnaire) è un questionario autosomministrato per valutare le informazioni sulla prevenzione secondaria nei pazienti con malattia coronarica (CAD). Lo scopo dello studio è quello di confrontare i risultati dell'applicazione del MICRO$Q$ in Italia e in Brasile.

Metodi: Gli strumenti sono stati somministrati a 500 pazienti coronarici (250 italiani e 250 brasiliani), 117 femmine e 383 maschi, età media 61,16 anni (Deviazione Standard = 9.74; ampiezza: 33-86), partecipanti ai programmi di riabilitazione cardiaca. Il MICRO-Q italiano è costituito da 26 item, 18 affermazioni vere, 8 false, con risposte vero, falso, non so, fornendo tre diversi punteggi: corretto, errato e incerto. Il MICRO-Q brasiliano ha 25 item, 18 affermazioni vere, 7 false, con le stesse risposte e punteggi. Per verificare e confrontare $i$ risultati è stato utilizzato un test $T$ per campioni indipendenti, ANOVA e Bonferroni Post-hoc.

Risultati: L'analisi della media complessiva delle indagini italiane e brasiliane ha mostrato differenze significative per le risposte corrette $(p<0,001)$ e per le risposte "non so" ( $p<0,001) .18$ items hanno presentato differenze significative $(p<0,005)$ tra $i$ questionari dei due paesi.

Conclusione: Nonostante le differenze tra l'Italia e il Brasile, l'analisi del questionario MICRO-Q ha mostrato una percentuale simile di risposte corrette, dimostrando un sufficiente livello di conoscenza relativo alla prevenzione secondaria della malattia coronarica.

Parole chiave: conoscenza, malattia coronarica, la riabilitazione cardiaca, questionario, differenze socio-economiche.

\section{References}

1. WHO Press. World Health Statistics 2008. Switzerland: World Health Organization, 2008. [updated 2008 May 20; cited 2009 March 2009]. Available from: www.who.int/whosis/whostat/2008/en/index.html.

2. WHO Press. The Global Burden of Disease: 2004 update. Switzerland: World Health Organization, 2008. [updated 2004; cited 2009 March 2009]. Available from: www.who.int/healthinfo/global_burden_disease/2004_ report_update/en/index.html.
3. Piegas LS, Avezum A, Pereira JCR, Neto JMR, Hoepfner C, Farran JA, et al. Risk factors for myocardial infarction in Brazil. Am Heart J 2003; 146: 331-8.

4. Cohen JD. ABCs of secondary prevention of CHD: easier said than done. Lancet 2001; 357: 972-73.

5. Calwell MA, Peters KJ, Dracup KA. A simplified education program improves knowledge, self-care behaviour, and disease severity in heart failure patients in rural settings. Am Heart J 2005; 150: 983.e7-12.

6. Albert MA, Glynn RJ, Buring J, Ridker PM. Impact of traditional and novel risk on the relationship between socioeconomic status and incident cardiovascular events. Circulation 2006; 114: 2619-26.

7. Sommaruga M, Vidotto G, Bertolotti G, Pedretti RF, Tramarin R. A self administered tool for the evaluation of the efficacy of health education interventions in cardiac patients. Monaldi Arch Chest Dis 2003; 60 (1): 7-15.

8. Ghisi GLM, Leite CM, Durieux A, et al. Validation for Portuguese of the Maugerl CaRdiac preventiOn-Questionnaire (MICRO-Q). Arq Bras Cardiol.2010; 94(3): 394-400.

9. Bethel H, Dalal H, Lewin R. Cardiac rehabilitation in the United Kingdom. Heart 2009; 95: 271-5.

10. Bradley C. Health beliefs and knowledge of patients and doctors in clinical practice and research. Patient Educ Counsel 1995; 26: 99-106.

11. Eriksson S, Kaati G, Bygren LO. Personal resources, motives and patient education leading to changes in cardiovascular risk factors. Patient Educ Counsel 1998; 34: 159-68.

12. Potvin L, Richard L, Edwards AC. Knowledge of cardiovascular disease risk factors among the Canadian population: relationships with indicators of socioeconomic status. Can Med Assoc J 2000; 162(9): S5-11.

13. Alm-Roijer C, Stagmo M, Uden G, Erhardt L. Better knowledge improves adherence to lifestyle changes and medication in patients with coronary heart disease. Journal of Cardiovascular Nursing 2004; 3: 321-30.

14. Kayaniyil S, Winstanley J, Parsons C, Brister S, Oh P, Stewart DG, Grace SL. Degree and correlates of cardiac knowledge and awareness among cardiac impatiens. $\mathrm{Pa}$ tient Educ Counsel 2009; 75: 99-107.

15. Cook PA, Bellis MA. Knowing the risk: relationships risk behavior and health knowledge. Public Health 2001; 115: 54-61.

16. Timmins F, Kaliszer M. Information needs of myocardial infarction patients. Eur J Cardiovasc Nurs 2003; 2: 57-65.

17. Kärner A, Göransson A, Bergdahl B. Patients' conceptions of coronary heart disease a phenomenographic analysis. Scand J Caring Sci 2003; 17(1): 43-50.

18. Scott JT, Thompson DR. Assessing the information needs of post-myocardial infarction patients: a systematic review. Patient Educ Counsel 2003; 50: 167-77.

19 Redfern J, Ellis E, Briffa T, Freedman SB. Development and testing of innovate patient resources for the management of coronary heart disease (CHD): a descriptive study. $\mathrm{Br}$ Med J 2006; 6: 95-104.

20. Hirani SP, Patterson DLH, Newman SP. What do coronary artery disease patients think about their treatments? An assessment of patients' treatment representations. $J$ Health Psychol 2008; 13: 311-22.

21. Ranjit N, Diez-Roux AV, Shea S, Cushman M, Ni H, Seeman T. Socioeconomic position, race/ethnicity, and inflammation in the multi-ethnic study of atherosclerosis. Circulation 2007; 116: 2383-90.

22. Kanjilal S, Gregg EW, Cheng YL, et al. Socioeconomic status and trends in disparities in 4 major risk factors for cardiovascular disease among US adults, 1971-2002. Arch Intern Med 2006; 199: 2348-55.

23. Albert MA, Glynn RJ, Buring J, Ridker PM. Impact of traditional and novel risk on the relationship between socioeconomic status and incident cardiovascular events. Circulation 2006; 114: 2619-26.

24. Muennig P, Sohler N, Mahato B. Socioeconomic status as an independent predictor of physiological biomarkers of cardiovascular disease: Evidence from NHANES. Am $J$ Prev Med 2007; 45: 35-40. 